etc.); and as a stimulant in all cases of indolent wounds. In the surgical and therapeutical clinics of the Academy Profs. $\mathbf{H}$. $\mathbf{H}$. Vlados and V. I. Kazansky have made over 700 injections of colloidal infusin. Patients have proved able to withstand large doses of the solution, and its value as a substitute and a stimulant has been proved.

Prof. N. A. Fedorov, M.D., Director of Experimental Laboratory, Blood Transfusion Institute. Academy of Medical Sciences, U.S.S.R.

\section{Monovular Twins}

I would like to place on record the following case of.twin labour which occurred at the Bosworth Park Infirmary, Market Bosworth, and which appears to confute the theory of $\mathrm{X}$ and $\mathrm{Y}$ chromosomes.

\section{CASE Report}

In a primipara aged 31 a twin pregnancy was diagnosed antenatally This was confirmed some three weeks before parturition by an $x$-ray photograph, which showed a vertex and a breech presenting. A week later the breech of the larger foetus seemed to be in front of the vertex of the smaller; so by simple external manipulation the latter was made to engage in the pelvic brim.

At the commencement of labour the diagnosis of vertex and breech was confirmed, and the vertex was found to be leading. Labour proceeded normally and expeditiously up to the birth of the first twin, a girl who weighed $5 \mathrm{lb}$. $2 \mathrm{oz}$. $(2.3 \mathrm{~kg}$.); the placenta, however, remained in situ, and its normal delivery was prevented by the head of the second twin following on the heels of the first, so that the second head engaged in the pelvic brim, and the presenting part became the vertex instead of the breech. The birth of the second child was complicated by the presence of the umbilical cord of the first, which latter was no doubt responsible for the imperfect flexion of the head, which resulted in a deep transverse arrest. With the aid of forceps the second twin, a boy of $6 \mathrm{lb} .12 \mathrm{oz}$. $(3.06 \mathrm{~kg}$.) was delivered 2 hrs. 20 mins. after the first.

The after-birth came away naturally after the second twin was born, and consisted of a single bag of membranes containing two placentae. There was no visible communication between the two placentae, nor was there any evidence, either macroscopically or by palpation, of the remains of an atrophied partition of membranes, which would have indicated the fusion of two gestation sacs into one. Mother and children are all doing well.

I am indebted to Dr. G. D. Kelly for permission to publish this case.

\section{G. H. PICKering, M.R.C.S., L.R.C.P.}

\section{Oedema of Vulva due to Toxaemia of Pregnancy}

The following case of vulval oedema obstructing normal delivery may be thought interesting enough to be put on record.

\section{CASE Report}

Mrs. B., a primigravida of 21 years, attended the antenatal clinic at this hospital throughout her pregnancy. She had no history of any cardiovascular or renal disease, and these systems were normal on examination. Her last menses started on June 19, 1945, the expected date of delivery therefore being'March 26, 1946. At first examination she appeared healthy, her blood pressure being $110 / 55 \mathrm{~mm}$. Hg. There was no oedema or albuminuria. Her pregnancy was uneventful until Feb. 15, when she complained of some swelling of her ankles. A fortnight later, at the 36th week of pregnancy, her B.P. was 150/95. On March 14, the 38th week, her B.P. was 150/105, and there was considerable albuminuria $(++)$, together with gros pitting oedema of legs and thighs, stretching up on to the anterio abdominal wall. Her face looked puffy and oedematous, but there was no oedema of her hands. She had vomited once during the previous night, but was free from visual symptoms and headaches.

On examination on admission there was also considerable pitting oedema of the vulva as well as of the legs and abdomen. The B.P. was $150 / 110$, and there was considerable albuminuria-5 parts per 1,000 . In spite of routine treatment, including fluid restriction, saltfree low-protein diet, and $3 \mathrm{mg}$. vitamin $B_{1}$ three times a day, the oedema did not decrease. The following day oedema of the vulva was greater but that of the legs was less. The labia majora and minora were grossly enlarged, as can be seen in the accompanying photograph. Her urine contained 6 parts of albumin per 1,000, and her B.P. was $140 / 110$.

By March 16 no improvement in her condition had occurred; her B.P. was $140 / 100$, albuminuria $5 \frac{1}{2}$ parts per 1,000 , and oedema greater still. Urinary output was persistently normal and satisfactory. Caesarean section was therefore performed, the indications being a severe pre-eclamptic toxaemia not responding to treatment, with gross oedema of vulva sufficient to obstruct any attempt at a normal delivery. The classical upper-segment operation was performed because of the impossibility of catheterization of the bladder due to the gross oedema. On opening the peritoneal cavity 1 to $1 \frac{1}{2}$ pints (568 to $852 \mathrm{ml}$.) of pale yellow. free fluid was found. This was removed. A normal male child weighing $6 \mathrm{lb} .1 \mathrm{oz}$. $(2.749 \mathrm{~kg}$. was delivered in good condition, and cried immediately. The mother's condition at the close of the operation was good.
Subsequentiy her progress was satisfactory. On the third day after operation she developed a temperature. There were no symptoms to account for this, and the oedema prevented a catheter specimen of urine or cervical swab being taken. The pyrexia soon settled with a course of sulphadiazine. The oedema subsided during the course of the next 10 to 14 days, her blood pressure rapidly fell to normal limits, and the albuminuria had disappeared after 10 days. On April 8 she was discharged from hospital in very good health. There was no oedema or albuminuria, and her B.P. was $120 / 85$. The infant weighed $6 \mathrm{lb} .6 \mathrm{oz}$. (2.89 kg.), was fully breast-fed and

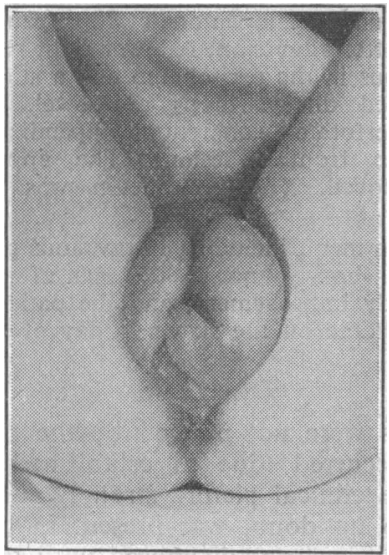

Showing the oedematous vulva, from a photograph taken on March 15 , the day before Caesarean section was performed.

in very good condition. The mother was subsequently seen at the postnatal clinic on May 1, 1946, six weeks after delivery, when she was still well, with no trace of oedema or albuminuria. B.P. was $130 / 70$. The child was progressing satisfactorily.

I wish to thank Mr. A. J. Wrigley and Mr. F. H. Finlaison for permission to publish this case, and Mr. M. G. Allen for the photograph.

St. Thomas`s Hospital, S.E.1.

$$
\text { J. P. Bush, M.R.C.S., L.R.C.P., }
$$

Resident Obstetric Officer.

\section{Modification of Ochsner and Mahorner Test for Patency of Deep Veins of Calf}

It is well established that before an cperative cure of varicose veins can be contemplated the patency of the other venous drainage of the leg-that is, the deep system-must be proved. At present there are two standard methods of doing this. The first is that of Ochsner and Mahorner, in which an Esmarch bandage is used to occlude the superficial veins; the onset of pain on walking indicates occlusion of the deep veins. Secondly, that of Delbet and Mocquet, which is based on the anatomical facts that there is free communication between the deep and superficial veins of the calf through the gastrocnemius and soleus and that contraction of those muscles plays a large part in the onward transmission of blood from the leg. When the patient walks with the superficial veins occluded by pressure the collapse of the veins below the pressure signifies patency of the deep veins. The test as decribed in Hamilton Bailey's Physical Signs in Clinical Surgery is a combination of the principles underlying these two tests. Both are rather laborious, and the modification to be described, based on these principles, seems to me more convenient and equally effective.

\section{THE Test}

When the incompetence of the saphenous valves has been proved by the presence of a " cough impulse" the thumb or fingers are laid over the great saphenous vein in the thigh with just sufficient pressure to occlude it. The patient is then asked to raise himself up and down on his toes, thus bringing the muscles of the calf into action. $\mathrm{He}$ continues to do this until either he complains of pain or the veins below the thumb are definitely seen to be emptying (this usually takes 15 to 30 seconds). The pressure in the thigh is then released, and the veins will be seen to refill rapidly from above. Any doubts as to their having emptied will be dispelled. If this emptying occurs the deep veins may be confidently stated to be patent.

This is a quick and convenient test and is chiefly of value when emptying occurs. If no collapse is seen, although the deep veins may be patent they should be regarded with suspicion. Further inquiry may reveal a history of old thrombophlebitis, which obviously contraindicates ligature.

\section{J. RASHleigh BelCher, M.S., F.R.C.S.}

St. Thomas's Hospital, Godalming, Surrey. 